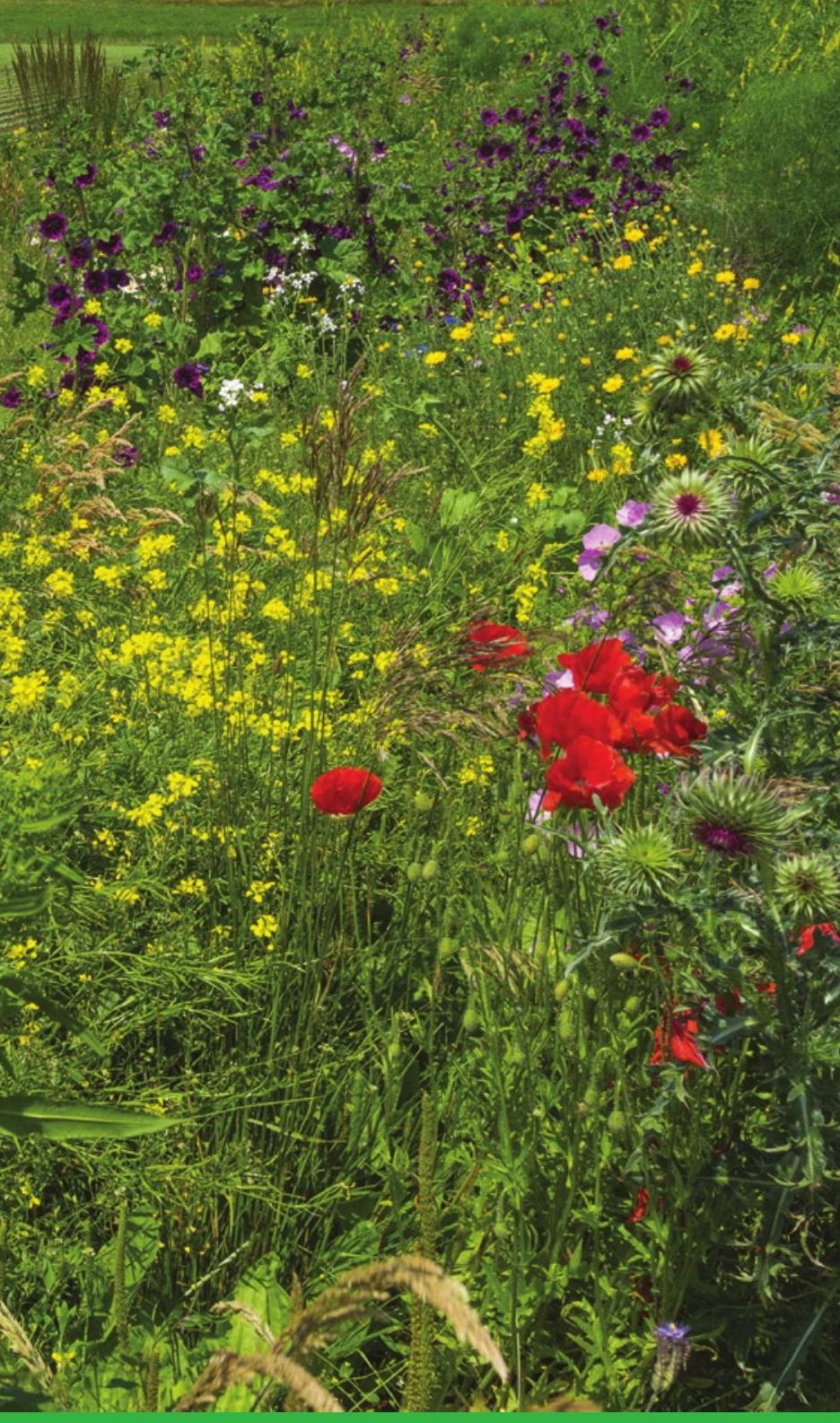

\title{
Arable weeds and non-target plants in prospective risk assessment for plant protection products
}

Specific protection goal and exposure assessment goal options

Gertie Arts, Jos Boesten, Theo Brock, Ivo Roessink 



\section{Arable weeds and non-target plants in prospective risk assessment for plant protection products}

Specific protection goal and exposure assessment goal options

Gertie Arts, Jos Boesten, Theo Brock, Ivo Roessink

This research was conducted by Wageningen Environmental Research (Alterra) and funded by the Dutch Ministry of Economic Affairs (project number BO-20-002-010).

Wageningen Environmental Research

Wageningen, October 2017

Report 2836

ISSN 1566-7197 
Arts, Gertie, Jos Boesten, Theo Brock, Ivo Roessink, 2017. Arable weeds and non-target plants in prospective risk assessment for plant protection products; Specific protection goal and exposure assessment goal options. Wageningen, Wageningen Environmental Research, Report 2836. 32 pp.; 7 fig.; 2 tab.; 23 ref.

In 2014 the European Food Safety Authority (EFSA) published a scientific opinion on the state of the science on risk assessment of plant protection products for non-target terrestrial pants (EFSA PPR, 2014). Before starting the development of EFSA guidance for this group of organisms, options for specific protection goals (SPGs) and related exposure assessment goals (EAGs) have to be defined. In this document, three options for in-field specific protection goals (SPGs) for arable weeds are proposed, comprising the options for Maximal weed reduction, Moderate weed reduction and Beneficial weed protection. Also for the off-field area, three SPG options are described, i.e. the 'Population recovery option' for non-target terrestrial plants, the 'Threshold option for vegetative growth of nontarget terrestrial plants' (this option is similar to the current procedure in the EU risk assessment) and the 'Threshold option for vegetative growth and generative reproduction of non-target terrestrial plants'. The described options serve to facilitate discussions on SPG and EAG at the EU level. This document explores and presents all options from a Dutch perspective. The agronomic consequences of the in-field and off-field options for specific protection goals have not been studied so far and need further elaboration and research.

Keywords: non-target terrestrial plants, protection goals, plant protection products, environmental risk assessment

The pdf file is free of charge and can be downloaded at https://doi.org/10.18174/424504 or via the website www.wur.nl/environmental-research (scroll down to Publications - Wageningen Environmental Research reports). Wageningen Environmental Research does not deliver printed versions of the Wageningen Environmental Research reports.

2017 Wageningen Environmental Research (an institute under the auspices of the Stichting Wageningen Research), P.O. Box 47, 6700 AA Wageningen, The Netherlands,

T +31 (0)317 4807 00, E info.alterra@wur.nl, www.wur.nl/environmental-research. Wageningen Environmental Research is part of Wageningen University \& Research.

- Acquisition, duplication and transmission of this publication is permitted with clear acknowledgement of the source.

- Acquisition, duplication and transmission is not permitted for commercial purposes and/or monetary gain.

- Acquisition, duplication and transmission is not permitted of any parts of this publication for which the copyrights clearly rest with other parties and/or are reserved.

Wageningen Environmental Research assumes no liability for any losses resulting from the use of the research results or recommendations in this report.

Wageningen Environmental Research Report 2836 | ISSN 1566-7197

Photo cover: Shutterstock 


\section{Contents}

$\begin{array}{ll}\text { Summary } & 5\end{array}$

$\begin{array}{ll}\text { Introduction } & 7\end{array}$

In-field specific protection goals and associated exposure assessment goals 11

3.1 Introduction

3.2 In-field specific protection goal options for arable weeds 11

3.2.1 Maximal weed reduction option $\quad 11$

3.2.2 Moderate weed reduction option $\quad 12$

3.2.3 Beneficial weed protection option $\quad 12$

3.2.4 Summary of in-field protection goal options for arable weeds $\quad 13$

$\begin{array}{lll}3.3 & \text { In-field exposure assessment goal options for arable weeds } & 14\end{array}$

$\begin{array}{lll}4.1 & \text { Off-field specific protection goal options for arable weeds } & 15\end{array}$

4.1.1 Population recovery option for non-target terrestrial plants $\quad 15$

4.1.2 Threshold option for vegetative growth of terrestrial non-target plants 16

4.1.3 Threshold option for vegetative and generative growth terrestrial non-target plants

$\begin{array}{lll}4.2 & \text { Off-field exposure assessment goal options for arable weeds } & 17\end{array}$

$\begin{array}{lll}5.1 & \text { Effect assessment scheme } & 19\end{array}$

5.1.1 Data requirements in EU Commission Regulations $\quad 19$

5.1.2 Effect assessment scheme in the Guidance Document on Terrestrial Ecotoxicology

5.1.3 Proposed specific protection goals and effect assessment schemes in the EFSA scientific opinion on non-target terrestrial plants

5.1.4 Recommendations from two recent SETAC Europe workshops

5.2 Exposure assessment scheme

5.2.1 Exposure assessment in the Guidance Document on Terrestrial Ecotoxicology

5.2.2 Exposure assessment in the current Dutch risk assessment 



\section{Summary}

In 2014 the European Food Safety Authority (EFSA) published a scientific opinion on the state of the science on risk assessment of plant protection products for non-target terrestrial plants (EFSA PPR, 2014). Before starting the development of EFSA guidance for this group of organisms, options for specific protection goals (SPGs) and related exposure assessment goals (EAGs) have to be defined. This document explores and presents SPG options and related EAG options from a Dutch perspective, which might be used to develop guidance on environmental risk assessment procedures for PPPs and arable weeds in in-field areas and non-target terrestrial plants in off-field areas. The described options serve to facilitate discussions at the EU level.

In this document, three options for in-field specific protection goals (SPGs) for arable weeds are proposed (see also Figure 1):

1. Maximal weed reduction option. This is the current option in the EU risk assessment.

Characteristics of this option are:

- Maximal provision of the ecosystem service 'crop production'.

- Lower priority for other ecosystem services provided by non-crop plants.

- No protection of non-crop plants in-field.

2. Moderate weed reduction option. Characteristics of this option are:

- Support of a certain moderate level of arable weeds in in-field areas.

- Support of several ecosystems services provided by non-crop plants, such as regulating services (e.g. prevention of erosion), supporting services (e.g. provision of habitat to invertebrates and food for farmland birds) and cultural services (e.g. protecting weeds of conservation concern).

- Improvement of local biodiversity relative to the current status.

- Effects on the ecosystem service 'crop production' is limited and controllable if implemented via a pre-defined in-field fraction of non-sprayed areas or conservation headlands.

3. Beneficial weed protection option. Characteristics of this option are:

- Protection of 'beneficial' and low-competitive non-target plants that could potentially be managed to maintain diverse ecosystem services.

- Control of weeds that hamper growth of crop plants and thus need to be controlled to secure crop production.

- Improvement of local biodiversity relative to the current status.

- Effects on the ecosystem service 'crop production' are less quantifiable because they are dependent on the availability of selective herbicides that control pernicious weeds but spare 'beneficial' ones.

For the off-field area, three options for specific protection goals (SPGs) are also described.

1. Population recovery option for non-target terrestrial plants. Characteristics of this option are:

- Effects on the vegetative growth/biomass of non-target terrestrial plants in the operational edge- of-field strip are accepted if:

- recovery takes place within an acceptable timeframe;

- effects in the operational nearby off-field strip are negligible.

- Effects on reproductive endpoints might occur in the operational edge-of-field strip.

- Least restrictive for the provision of the in-field ecosystem service 'crop production'.

- Sustainable plant populations at the landscape level are likely not at stake under the condition that in the agricultural landscape enough ecological focus areas are available ( $7 \%$ is proposed in the reform of the Common Agricultural Policy [EC, 2013a]).

2. Threshold option for vegetative growth of non-target terrestrial plants (this option is similar to the current procedure in the EU risk assessment). Characteristics of this option are:

- Effects on the vegetative growth/biomass of non-target terrestrial plants in the operational edge-of-field strip are negligible.

- Effects on reproductive endpoints might occur at the local level.

- Sustainable plant populations at the landscape level are likely not at stake. 
Threshold option for vegetative growth and generative reproduction of non-target terrestrial plants. Characteristics of this option are:

- Effects on the vegetative growth/biomass and on generative endpoints (flower and seed production; viability of seeds) of non-target terrestrial plants in the operational edge-of-field strip are negligible; - Improvement of sustainability of plant populations and biodiversity at local and landscape level.

Within all three possibilities for off-field SPGs, two options are proposed for the spatial unit of the exposure assessment goal (EAG). The two options are either a 10-cm or a 2-m width of off-field strip in the edge-of-field area (and for SPG option 1 in the nearby off-field area as well; see Figure 1) for which these three possible SPGs are assessed. This $10 \mathrm{~cm}$ is considered a minimum width from a scientific point of view because a plant cannot grow on e.g. a 1-mm strip. The background for offering these options is that spray drift is the most important exposure route and that spray drift deposition decreases sharply with distance from the treated field. Thus protecting a $10-\mathrm{cm}$-wide strip leads to higher exposure estimates (e.g. a factor of two) than protecting a 2-m-wide strip.

Agronomic consequences of the in-field and off-field options for specific protection goals have not been studied so far and need further elaboration and research. 


\section{Introduction}

The naturally occurring floras found within the cropped area of arable fields are typically viewed negatively within the context of profitable crop production, due either to competition for resources or reduced crop quality. The fact that these plants are called weeds implies that they are generally unwanted in areas where crops are grown. In conventional agriculture it is common practise to reduce the growth of unwanted weeds in crops by applying herbicides. Arable weeds, however, have also been shown to have ecological functions for higher trophic groups. For example, their seeds are found in the diets of farmland birds and are particularly important for over-winter survival. Arable weeds also support a number of invertebrate groups, some of which may also be an important source for birds during the winter season, serve as pollinators of crops (e.g. wild bees) or can be considered natural enemies of crop pests (Storkey \& Westbury, 2007).

Increasing in-field ecological compensation areas have been promoted as a means to achieve environmentally sustainable increases in crop yields by enhancing ecosystem functions that regulate and support crop production. Pywall et al (2015) experimentally demonstrated for a 900 ha commercial arable farm in central England that wildlife-friendly management which supports ecosystem services is compatible with conventional crop yields. Their research suggests that in removing $3-8 \%$ of land from production at the field edge in order to create a wildlife habitat, there would be no adverse impact of this measure on overall yield in terms of monetary value or nutritional energy over a 5-year crop rotation.

In the reform of the Common Agricultural Policy (CAP) of the European Union it is proposed (under Pillar 1 ) that $3-5 \%$ of EU farmland should be managed as ecological focus areas in order to halt biodiversity loss, and that this area should be increased to 7\% by 2017 (EC, 2013a). Such ecological focus areas could include land left fallow (land left unsown after being ploughed), buffer strips, hedgerows and off-field natural and semi-natural habitats. These areas should provide sufficient habitats for wild plant and animal species and should facilitate dispersal of species across the landscape (EC, 2010). In the Netherlands about 66,000 agricultural holdings manage about 20,000 square kilometres of land, of which $92 \%$ is utilised as agricultural area. The remaining $8 \%$ is occupied by (semi-) natural habitats, stables and farmyards (CBS, 2015). Recently, Cormont et al. (2016) evaluated the CAP target on natural elements for the Netherlands. They assessed the effects of the density of natural elements in agricultural landscapes on multi-taxon species richness, including vascular plants, breeding birds, butterflies, hoverflies, dragonflies and grasshoppers. They found that species richness increased either as a linear (e.g. for vascular plants) or as a logarithmic function (e.g. for butterflies and birds) of the proportion of natural elements in the landscape. Dutch landscapes with 3-7\% of natural elements harboured generally $37-75 \%$ of maximum species richness (Cormont et al. 2016).

Considering the above, promoting biodiversity in agroecosystems with an acceptable impact on crop yield may require that low weed populations are to be tolerated within cropped fields or that ecological compensation areas within agricultural fields are created (Storkey \& Westbury, 2007), particularly if off-field semi-natural and natural habitats are limited in the agricultural landscape. Furthermore, according to current legislation the agricultural use of herbicides should not result in unacceptable ecological effects on plants in off-field habitats. Off-field habitats surrounding cropped fields may be subject to spray-drift and/or surface run-off exposure. Note that the target terrestrial plant in cropped areas may be considered as non-target terrestrial plants in off-field areas.

In 2014 the European Food Safety Authority (EFSA) published a scientific opinion on the state of the science on risk assessment of plant protection products for non-target terrestrial pants (EFSA PPR, 2014). This EFSA Scientific Opinion does not have the status of an official guidance document, but the information and recommendations provided can be used as building blocks for future guidance. Before developing EFSA guidance for assessing the environmental risk of PPP exposure on arable weeds and 
non-target terrestrial plants, however, options for specific protection goals (SPGs) and related exposure assessment goals (EAGs) have to be defined. The definition and selection of SPGs and EAGs requires a dialogue between risk assessor and risk managers (e.g. those of SCoPAFF, the Standing Committee on Plants, Animals, Food and Feed, in which risk managers of EU Member States are represented).

When defining SPGs and related EAGs for arable weeds and non-target terrestrial plants, the responsibility of risk assessors is (i) to acknowledge existing general protection goals and regulatory data requirements, (ii) to propose possible SPG options and related EAG options, and (iii) to describe the possible environmental consequences of each option. The risk assessors should propose realistic SPG and EAG options and the interrelationships between the presented proposals in a concise and transparent manner. What represents a tolerable level of risk to arable weeds and terrestrial nontarget plants and whether a PPP can be placed on the market for a specific use is decided by risk managers (EFSA PPR, 2010; EFSA SC, 2016).

The procedure includes the further development of scientific criteria guiding spatial and temporal differentiation of SPGs and related EAGs from an environmental point of view. A transparent dialogue will not only assist risk managers in making more informed decisions on (economic) trade-offs, but will also help risk assessors to focus their efforts on the development of environmental risk assessment schemes that address the SPG and EAG options selected by risk managers.

The objective of this document is to explore and present SPG options and related EAG options that might be used to develop guidance on environmental risk assessment procedures for PPPs and arable weeds in in-field areas and non-target terrestrial plants in off-field areas. These options will be formulated from a Dutch perspective to facilitate discussions at the EU level. 


\section{Definitions}

In defining SPGs and related EAGs for non-target terrestrial plants it is important to have clear definitions of terms like field margin, edge-of-field, in-field area, off-field area, in-crop area, off-crop area, buffer strip area and minimum agronomic crop-free zone. For clarity a definition of these terms is given below. How the different areas relate to each other is visualised in Figure 1.

In-field area: The crop area and its boundaries (e.g. minimum agronomic crop-free zone, buffer strip, ecological compensation area such as areas sown with seed mixes to encourage flowering plants, flower-visiting insects and food for birds) owned and/or managed by a specific farmer in the context of crop management.

Off-field area: The area outside the managed 'in-field' area. It can encompass neighbouring fields where other crops are grown as well as semi-natural (e.g. drainage ditches, hedgerows) and natural (e.g. patches of woodland) habitats.

Field margin: The border between the in-field and off-field area.

Edge-of-field area: The off-field area between the in-field area and the nearby off-field area. The field margin is its inner border while the boundary between the edge-of-field area and the nearby off-field area is its outer border (see Figure 1 ).

Operational edge-of-field strip: The off-field strip that starts at the field margin and where the specific protection goals and related exposure assessment goals apply for non-target terrestrial plants in edge-of-field habitats. In this document two spatial unit options for the width of this regulatory edge-off-field strip are proposed, viz., $10 \mathrm{~cm}$ and $2 \mathrm{~m}$.

Nearby off-field area: The off-field area further away from the treated field and that borders the edgeof-field strip.

Operational nearby off-field strip: A strip of nearby off-field area that starts at the outer border of the edge-of-field area and where the specific protection goals and related exposure assessment goals apply for non-target terrestrial plants in the nearby off-field area. In this document two spatial unit options for the width of this regulatory nearby off-field strip are proposed, viz., $10 \mathrm{~cm}$ and $2 \mathrm{~m}$.

In-crop area: In-field area used by the farmer to grow a specific crop. It concerns both the surface covered by the crop plants including the space between the crop rows.

Off-crop area: Off-field area as well as in-field area not used by the farmer to grow a specific crop.

Crop-free buffer strip: Non-cropped in-field area between field margin and minimum agronomic cropfree zone. A non-cropped buffer strip may consist of bare soil or vegetation other than the crop. In the Netherlands a buffer strip should always be crop-free.

Cropped buffer strip: In-field area where the crop is present but that is not sprayed and is located between the sprayed crop and the minimum agronomic crop-free strip.

Conservation headlands and wildlife strips: In-field ecological compensation area along the edge or at the corners of an agricultural field that aim to promote biodiversity (e.g. flowering weeds, insects, birds). These in-field ecological compensation areas usually are part of environmental stewardship schemes. These areas are usually not directly sprayed and this may serve as a buffer strip to minimise the exposure of off-field habitats. The farmer may be financially compensated for creating these ecological compensation areas.

Minimum agronomic crop-free strip: Because of the use of machinery (e.g. ploughs, tractors, spraying machines) there will always be a certain distance between the field margin and the area of the field that is directly accessible by the machinery. This distance is called the minimum agronomic crop-free strip. According to Van de Zande et al. (2012) the width of the minimum agronomic crop-free strip is $0.25 \mathrm{~m}$ for grass and cereals, $0.75 \mathrm{~m}$ for crops grown on ridges, $3 \mathrm{~m}$ for orchards, $2 \mathrm{~m}$ for avenue trees and $0.5 \mathrm{~m}$ for all other arable crops. 


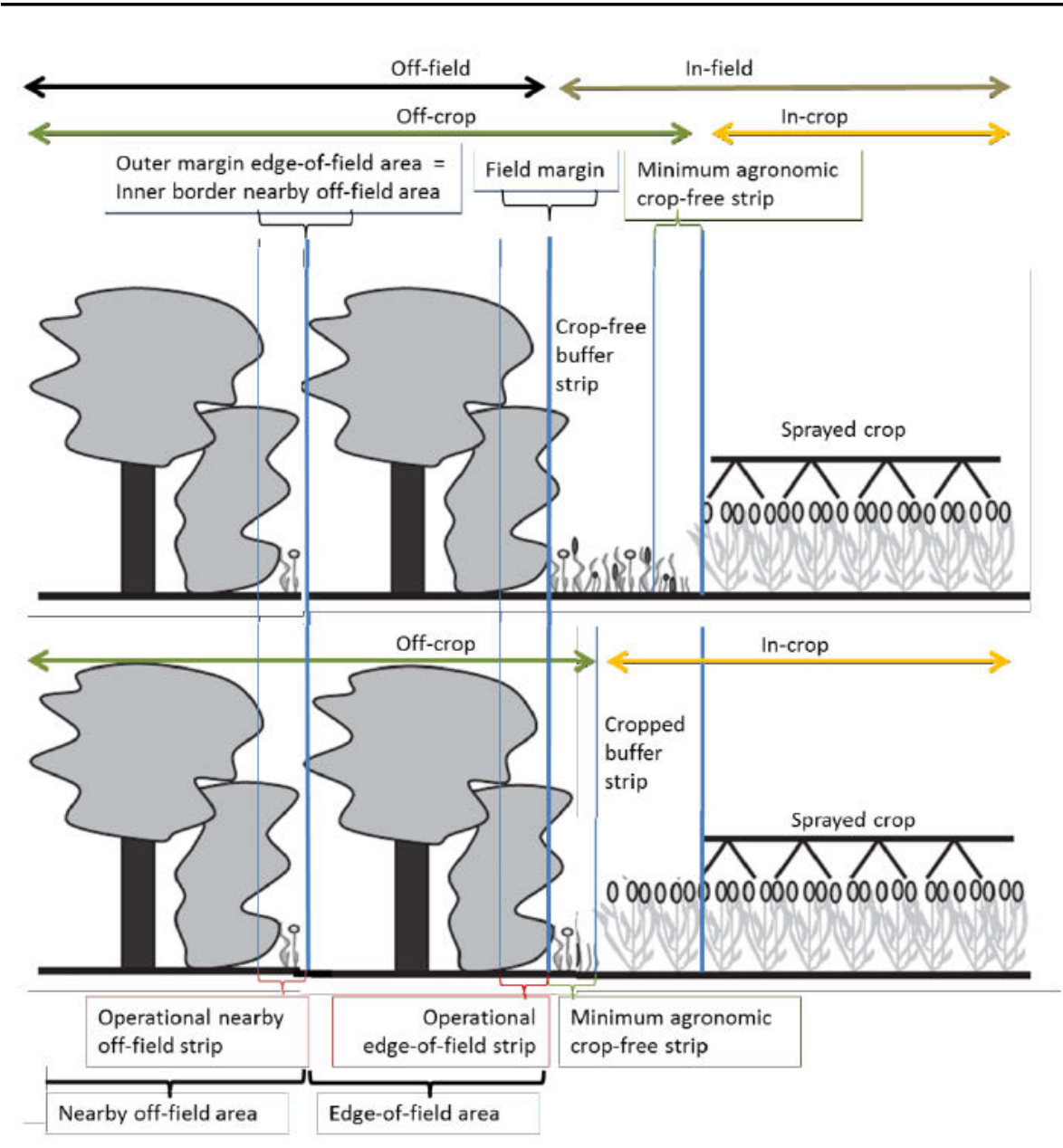

Figure 1 Schematic representation of a crop (in-crop area) bordered by at least an in-field minimum agronomic crop-free strip and an off-field woodland habitat (lower part of Figure 1) or an infield minimum agronomic crop-free strip, a crop-free buffer strip and an off-field woodland habitat (upper part of Figure 1). Note that in the Netherlands a crop-free buffer strip is mandatory. Figure adapted after Alix et al. (2012) and Van de Zande et al. (2012).

In the upper part of Figure 1 the off-crop but in-field area comprises a crop-free buffer strip (management option selected by the farmer to minimise spray drift exposure in off-field habitats) and a minimum agronomic crop-free zone that is obligatory. The sum of the widths of the crop-free buffer strip and the minimum agronomic crop-free zone is the total in-field zone not directly sprayed. In some EU Member States, but not in the Netherlands, it is possible to use an unsprayed cropped buffer strip to minimise spray drift exposure in off-field habitats (lower part of Figure 1). Although in Figure 1 the off-field area comprises trees and shrubs, the off-field area may be diverse, comprising fields with other crops, drainage ditches, herbaceous vegetation etc. 


\section{$3 \quad$ In-field specific protection goals and associated exposure assessment goals}

\subsection{Introduction}

This section deals with specific protection goals (SPGs) and related exposure assessment goals (EAGs) for non-crop terrestrial plants in in-field areas. The buffer strip and the minimum agronomic crop-free strip are located in-field and for these areas the same specific protection goal applies as for the in-crop area (otherwise buffer strips are needed to protect the non-crop vascular plants in the buffer strip, which is neither practical nor feasible from an agronomic point of view). Note, however, that buffer strips and the minimum agronomic crop-free strips also have an important function to mitigate exposure of the off-field area (drift and run-off reduction). Since buffer strips and the minimum agronomic crop-free strips receive lower pesticide loads (including herbicides) they may also serve as a refuge area for certain arable weeds.

The specific protection goals for in-field ecological compensation areas (e.g. conservation headlands and wildlife strips) for which the farmer receives financial compensation, however, may be more strict than those for the in-crop area. The specific protection goals and related exposure assessment goals for these ecological compensation areas are not discussed here since they need to be tailor-made, dependent on the objectives of the financial compensation that the farmer receives.

If the goal is to protect populations of certain red-list arable weeds in certain areas this can best be achieved locally by implementing specific conservation measures that may require the status of a nature conservation area or financial compensation of the owner of these areas to achieve this goal.

\subsection{In-field specific protection goal options for arable weeds}

\subsubsection{Maximal weed reduction option}

This option selects the provisioning ecosystem service 'crop production' (e.g. food, fibre and fuel) as being of primary importance. This implies that for the farmer the monetary value of the crop is prioritised over other ecosystem services that may also be provided by arable weeds such as regulating services (e.g. prevention of erosion), supporting services (e.g. provision of habitat to invertebrates) and cultural services (e.g. protecting weeds of conservation concern). This option considers all non-crop plants in the cropped area as weeds that need not be protected. Consequently, herbicides can be applied to erase arable weeds in in-crop areas under the following conditions:

- Herbicide application is not in conflict with human health criteria (e.g. acceptable levels of residues on harvested crop [food commodities])

- Herbicide application is not in conflict with other environmental criteria (e.g. sufficient protection of in-soil organisms, acceptable exposure concentrations in off-field habitats and groundwater)

- Herbicide application does not have a negative impact on crop rotation

- Exposure concentrations of the herbicide decline in such a way that effects on vascular plants are absent during the next growing season (e.g. to allow the establishment of future in-field ecological compensation areas).

The ecological consequence of this option is that the in-crop area may be almost devoid of arable weeds during the entire growing season of the crop. In agricultural landscapes this may directly (e.g. reducing species richness and abundance of vascular plants) and/or indirectly (e.g. reducing species richness and abundance of animals that depend on arable weeds) reduce local biodiversity, particularly if the proportion of crop-free (semi-) natural habitats is small (e.g. less than the 7\% CAP proposal) and/or the field sizes are large. Note that field edges are commonly found to support more (weed) species than field centres since they receive more propagules (e.g. seeds) from neighbouring habitats. 
According to Hardman et al (2015) three broad mechanisms can be mentioned by which local habitat diversity, and consequently local biodiversity, can be decreased: (i) decreased non-crop habitat diversity, (ii) decreased crop diversity and intensification of agronomic practises (e.g. fertiliser and pesticide use) and (iii) increasing the grain of the agricultural landscape by increasing field size (e.g. through removing semi-natural elements like hedgerows). Considering the above, the ecological consequences of the 'maximal weed reduction option' need to be evaluated in light of local properties of the agricultural landscape.

\subsubsection{Moderate weed reduction option}

This option differs from the 'maximal weed reduction option' in that it also aims to support the presence of a certain moderate level of arable weeds in in-field areas to support several ecosystem services provided by these weeds, such as regulating services (e.g. prevention of erosion), supporting services (e.g. provision of habitat to invertebrates and food for farmland birds) and cultural services (e.g. protecting weeds of conservation concern).

This option may be achieved by (a) reducing the herbicide applications in such a way that in the total in-crop area a certain biomass of arable weeds remains present (i.e. $10 \%$ of the biomass that would be available when not applying weed control measures) or (b) by implementing non-spray crop areas along the edge and/or at the corners of an agricultural field while for the remaining in-crop area a maximal weed reduction may apply. This latter option is more controllable and predictable for the farmer. When selecting (b) the relative proportion of non-spray crop area should be the same (i.e. $10 \%$ ) for small and large fields so that the width of the non-sprayed strip of cropped area along the field edge should be wider if the sizes of the fields are larger.

The economic consequence of this option may be that the monetary value of the crop decreases due to competition of the crop with arable weeds. Where arable weeds are allowed to persist in in-field areas, it is important to take into account potential seed return, which may increase the weed burden in subsequent crops. Arable weeds, however, may also provide ecosystem services profitable for agriculture like water and erosion regulation and natural pest regulation by invertebrates that are supported by arable weeds, so that the loss of crop when implementing this option may be relatively small. From a farmer's point of view the above-mentioned sub-option (b) may be easier to implement and easier to control.

A possible drawback of both sub-options is that it may not be easy to observe whether the required measures (reduced herbicide application in total crop area [sub-option a] or the establishment of nonsprayed crop areas [sub-option b]) really are implemented. Alternatively, the non-sprayed crop areas can be replaced by vegetation other than the crop (e.g. by establishing grass buffer strips or seeding seed mixes with a high diversity of flowering plants). Although these types of vegetation have been shown to deliver clear ecosystem services benefits, they can also have a negative impact on existing arable weeds (see Storkey \& Westbury [2007] and literature cited therein) since other terrestrial plants may become dominant there and outcompete the typical arable weeds on these crop-free buffer strips.

The ecological consequences of 'the moderate weed reduction option' are that in the in-crop area a certain biomass of arable weeds is maintained during the growing season so that these weeds can provide some ecosystem services and that local biodiversity is improved.

\subsubsection{Beneficial weed protection option}

This option makes a distinction between pernicious weeds that need to be controlled to secure crop production and 'beneficial' weeds with ecosystem service provision value and low competitive ability. Marshall et al (2003) and Storkey \& Westbury (2007) mention a range of such arable weed species common in the United Kingdom on the basis of their competitive index and their potential value as a resource to invertebrates and farmland birds. These authors mention 'beneficial' weeds that could potentially be managed to reconcile diverse ecosystem services with crop production. These weeds comprise the spring-germinating species Polygonum aviculare, Sinapsis arvensis, Chenopodium album and Persicaria maculosa, and autumn-flowering ruderals such as Stellaria media, Poa annua, Senecio vulgaris, Cerastium fontanum, Lamium purpureum, Capsella bursa pastoris and Veronica persica. These weeds generally grow below the crop canopy, forming an understorey and avoiding crop competition for light. They utilise, in part, resources that the crop is unable to capture. In this sense, it 
is possible to achieve a 'win-win' situation where weed biomass (including their seeds) is provided to support invertebrates and farmland birds with a minimal crop yield loss. It needs of course to be investigated which common arable weed species in the Netherlands have a low competitive ability with crop species and support similar ecosystem services.

The fundamental challenge of the 'beneficial weed protection option' is to maintain effective in-crop control of problem weeds while sustaining beneficial species at economically acceptable levels. Within a plant protection product context, the application of selective herbicides is a tool in meeting this challenge.

The agronomic and economic consequences of the 'beneficial weed protection option' may be that (a) herbicides that selectively control pernicious weeds and spare 'beneficial' weeds need to be available; (b) the use of these selective herbicides may be more expensive; and (c) that under certain environmental conditions 'beneficial' weed species might still have the potential to inflict serious crop yield losses, since weed competition has been shown to vary between sites and years (Storkey \& Westbury, 2007).

The ecological consequence of the 'beneficial weed protection option' is that in the in-crop area, populations of 'benificial weeds' are protected so that these weeds can provide essential ecosystem services to support local biodiversity (e.g. invertebrates and farmland birds).

\subsubsection{Summary of in-field protection goal options for arable weeds}

The specific protection goal dimensions proposed by EFSA PPR (2010) are: (1) Ecological entity to be protected, (2) Attribute to be protected, (3) Magnitude of tolerable effect, (4) Temporal scale of tolerable effect and (5) Spatial scale of tolerable effect. Our proposal for in-field specific protection goal options for arable weeds is presented graphically below (Figure 2).

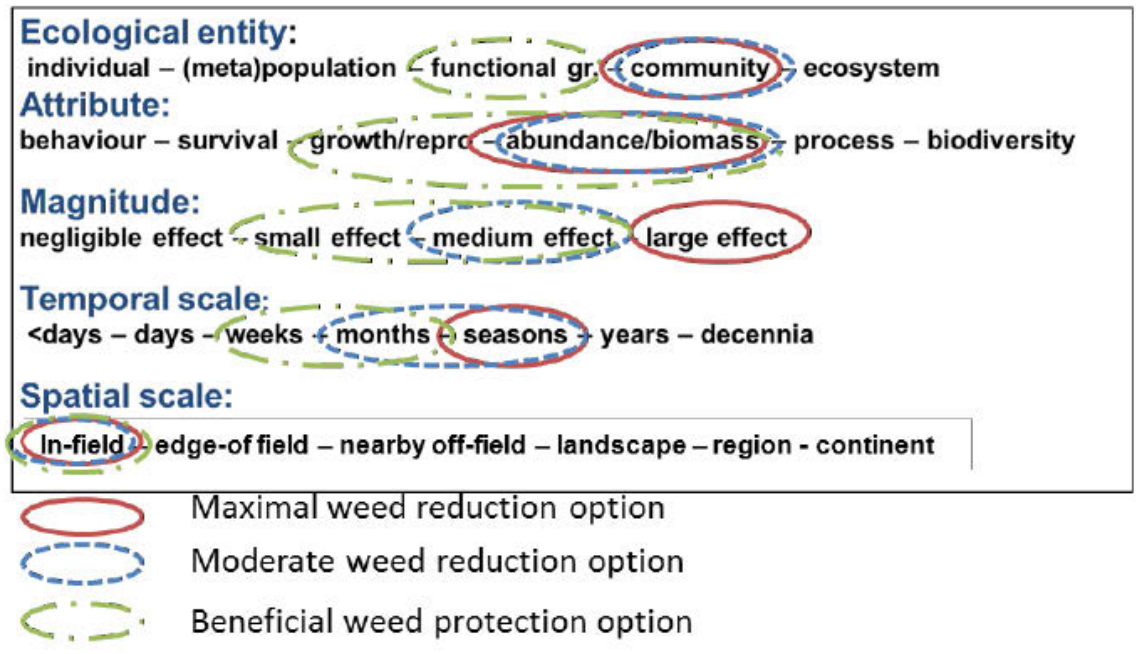

Figure 2 Schematic representation for in-field protection goals for arable weeds.

The spatial scale is set at the in-field level for all three options. For the 'Maximal weed reduction option' the ecological entity considered is the community of arable weeds and its attribute the total biomass of the arable weed community, while the magnitude of tolerable effect is large during the seasons in which the crop is grown. For the 'Moderate weed reduction option' the ecological entity and attribute considered are again community and total biomass, while the magnitude of tolerable effect is medium for months to seasons. For the 'Beneficial weed protection option' the ecological entity considered is the functional group of beneficial weeds and its attribute the growth/reproduction/biomass of these beneficial weeds, while the magnitude of tolerable effect is medium for weeks and small for months. Effects on the functional group of pernicious weeds, however, may be large and longer-term (seasons). 


\subsection{In-field exposure assessment goal options for arable weeds}

The three SPG options for in-field arable weeds consider all weed populations in the treated field. As a result, the exposure assessment goal (EAG) for these three options is the same at least in the sprayed in-crop area.

The first element of the EAG is the Ecotoxicologically Relevant Exposure Quantity (EREQ). If the effect of the pesticide is mainly the result of contact exposure, the EREQ is the mass of pesticide per surface area of the weed leaves. If the effect of the pesticide is mainly the result of uptake of pesticide through the roots, the EREQ is the pore water concentration in the top centimetre of the soil. This top centimetre is selected because herbicides are mostly applied in spring when weeds are still small or have not yet emerged. It is usually known from the mode of action whether the activity of the pesticide is mainly through contact or through uptake from the soil.

The second element of the EAG is the temporal dimension of the selected EREQs. It is proposed to use the annual peaks of both EREQs. The third element is the spatial unit. This splits into the type of spatial unit and the size or surface area over which concentrations may be averaged. The type of spatial unit is the cropped area of an agricultural field where the pesticide is applied. The surface area over which concentrations may be averaged is a point of discussion. The roots or leaves of an emerging weed will develop in a circle with a diameter of $1-10 \mathrm{~cm}$, so a surface area ranging from 1 to $100 \mathrm{~cm}^{2}$. The spatial variability of concentrations at such a surface area is considerable (CVs of around $50 \%$ can be expected). Averaging over the whole field then seems inappropriate because there may be no effect based on the average concentration in the field while $20 \%$ of the weeds may be exposed to concentrations that result in serious effects. Therefore it is tentatively proposed to average over a surface area of $100 \mathrm{~cm}^{2}$.

The fourth element is the spatial statistical population of spatial units. This population consists of all fields where this pesticide is applied (in the area of use of the pesticide). The fifth element is the multi-year temporal population of EREQ values. This population is proposed to consist only of values from the years in which the pesticide is applied, as these years generate the maximum EREQ values. The sixth element is the percentile to be taken from the spatio-temporal population of EREQ values. It is proposed to take the $90^{\text {th }}$ percentile from the spatio-temporal population of EREQ values without prescribing any restrictions to the spatial or temporal percentiles. In principle, this $90^{\text {th }}$ percentile may be replaced by e.g. a $70^{\text {th }}$ or $80^{\text {th }}$ percentile but the $90^{\text {th }}$ percentile has become more or less a standard approach in the EU regulatory exposure assessment. 


\section{$4 \quad$ Off-field specific protection goal options for non-target terrestrial plants}

\subsection{Off-field specific protection goal options for arable weeds}

\subsubsection{Population recovery option for non-target terrestrial plants}

The PPP Regulation requires a high level of protection of non-target terrestrial plants in off-field areas. Following the recommendations of EFSA PPR (2014), and to ensure ecosystem services provided by non-target terrestrial plants in off-field areas, they need to be protected at the population level. In the EFSA Aquatic Guidance Document (EFSA PPR, 2013), which also deals with protection goals for offfield habitats, a distinction is made between an ecological recovery option (ERO) and an ecological threshold option (ETO). Here we follow more or less the same lines of reasoning. The 'population recovery' option described in this section resembles the ERO option for aquatic organisms in edge- offield surface waters.

The 'population recovery option' accepts some population-level effect on the vegetative growth/biomass of non-target terrestrial plants in the operational edge-of-field strip if recovery takes place within an acceptable time-period and it is ensured that further off (in the nearby off-field area; see Figure 1) no effects of herbicide exposure on the abundance/biomass of these populations will occur. Consequently, when selecting this option the location of the operational nearby off-field strip should be precisely defined in consultation with risk managers.

For the 'population recovery option' the ecological entity considered is the population of non-target terrestrial plants (including vulnerable species) and its attribute abundance/biomass, while the magnitude of tolerable effect in the operational edge-of-field strip is medium for weeks or small for months. In addition, in the operational nearby off-crop strip (at x m away from the field margin) the magnitude of tolerable effect on abundance/biomass of populations of non-target terrestrial plants (including vulnerable ones) should be negligible (see Figure 3 of SPG dimensions for this option below).

The ecological consequence of this option is that although the tolerable impact on the abundance/biomass of potentially vulnerable non-target terrestrial plants may be limited, the flower and seed production of these plants in the operationally defined edge-of-field area may be impacted to a larger extent.

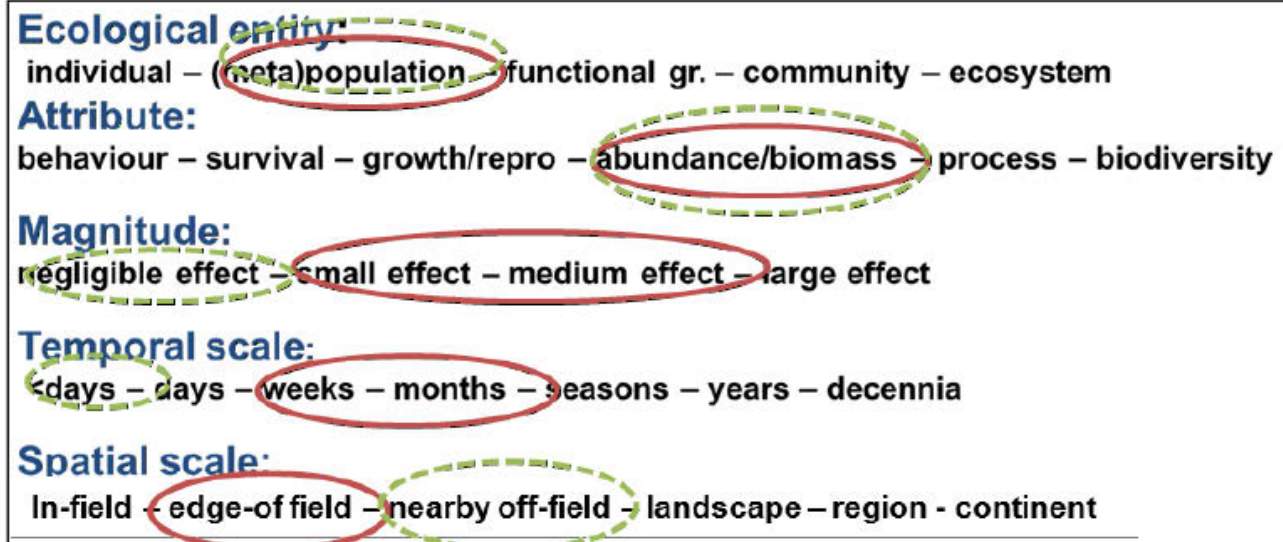

Figure 3 Schematic representation of off-field protection goals for arable weeds based on the population recovery option. 


\subsubsection{Threshold option for vegetative growth of terrestrial non-target plants}

The 'threshold option for vegetative growth' does not accept effects on the vegetative growth/biomass of non-target terrestrial plants in the operationally defined edge-of-field strip (see Figure 1). This option, however, does not guarantee that the flower and seed production of these plants is not impacted in the operational edge-of-field strip but assumes that this is not necessarily problematic if in nearby off-field habitats the production of flowers and viable seeds is not impacted by herbicide exposure.

For the 'threshold option for vegetative growth' the ecological entity considered is the population of non-target terrestrial plants (including vulnerable species) and its attribute abundance/biomass of the non-target plant population, while the magnitude of tolerable effect in the operational edge-of-field strip is negligible (see Figure 4 of SPG dimensions for this option below).

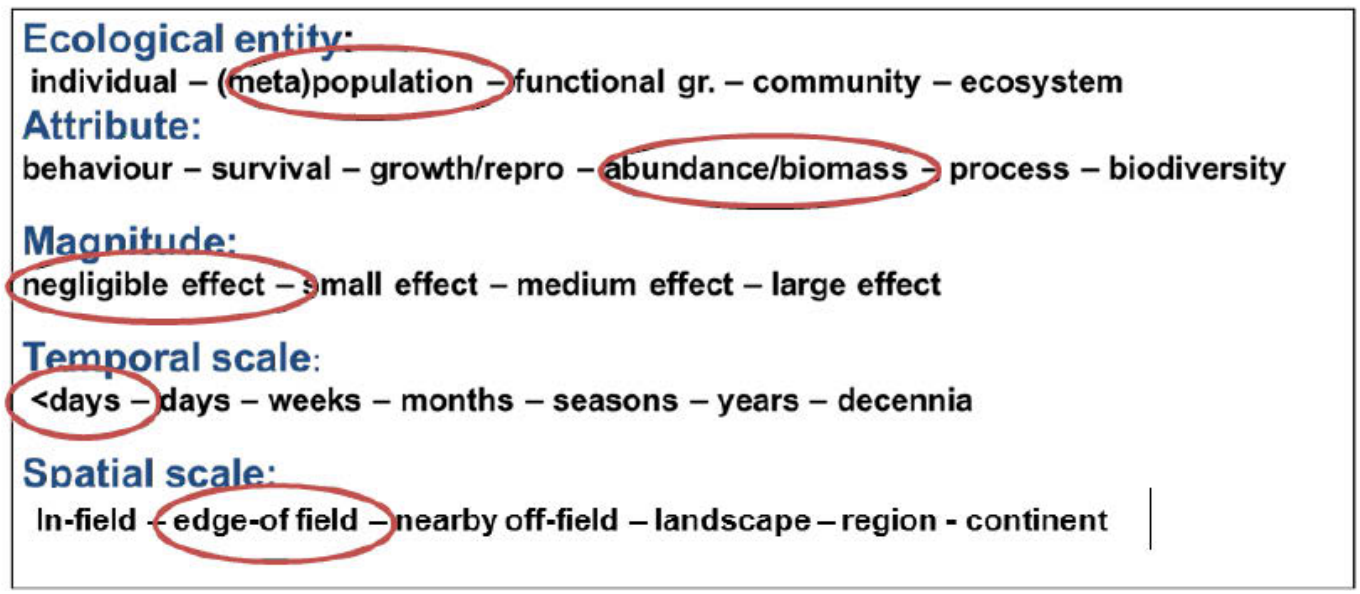

Figure 4 Schematic representation of off-field protection goals for arable weeds based on the vegetative growth option.

The ecological consequence of this option is that although the tolerable impact on the abundance/biomass of potentially vulnerable non-target terrestrial plants is negligible, the flower and seed production of these plants in the operationally defined edge-of-field area may be impacted to some extent. The economic consequence of this option in comparison to the population recovery option' is that it may require a wider in-field buffer strip as a mitigation measure to sufficiently reduce the herbicide exposure in the operational edge-of-field strip. 
4.1.3 Threshold option for vegetative and generative growth terrestrial non-target plants

The 'threshold option for vegetative and generative growth' does not accept effects on both vegetative growth/biomass and on flower and viable seed production of non-target terrestrial plants in the operational edge-of-field strip. Note that this option may require adjusted ecotoxicological tests with terrestrial plants, since most (OECD) standard toxicity tests with terrestrial vascular plants only address treatment-related effects on vegetative measurement endpoints.

For the 'threshold option for vegetative and generative growth' the ecological entity considered is the population of non-target terrestrial plants (including vulnerable species) and its attribute growth/reproduction and abundance/biomass of the non-target plant population, while the magnitude of tolerable effect in the operational edge- of-field strip is negligible (see Figure 5 of SPG dimensions for this option below).

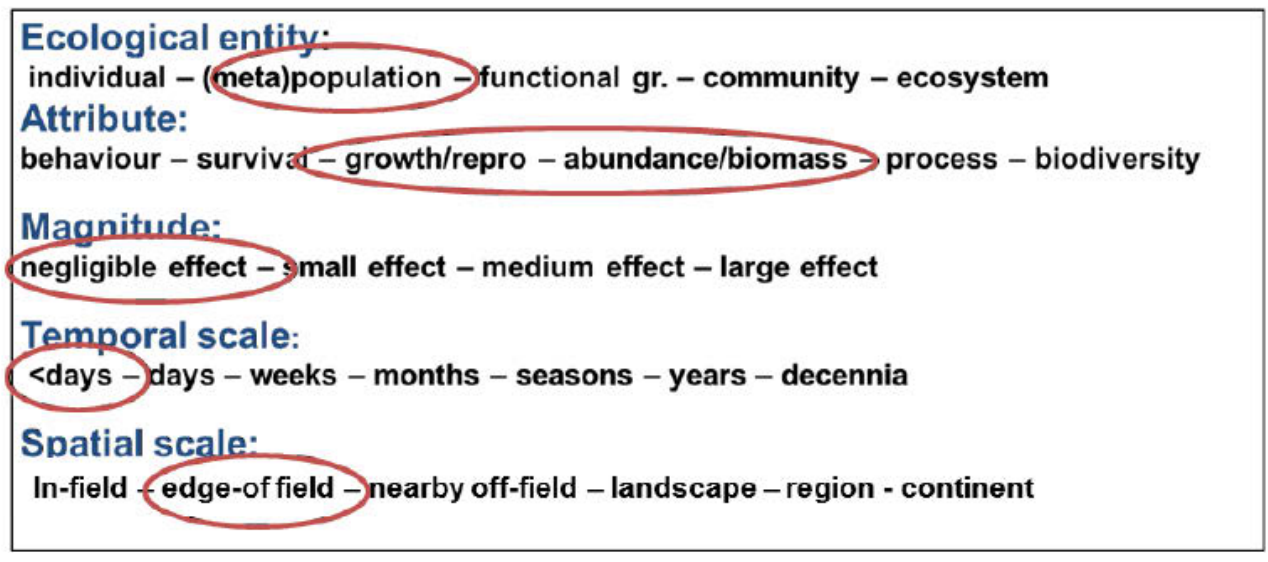

Figure 5 Schematic representation of off-field protection goals for arable weeds based on the generative growth option.

This option provides the highest protection level for non-target terrestrial plants in off-field areas that can be applied in prospective ERA. The economic consequence of this option in comparison to the other off-field SPG options is that it may require an even wider in-field buffer strip as a mitigation measure to sufficiently reduce the herbicide exposure in the operationally defined edge-of-field strip.

\subsection{Off-field exposure assessment goal options for arable weeds}

The Ecotoxicologically Relevant Exposure Quantity (EREQ) for the off-field SPGs is the same as for the in-field SPGs, so the mass of pesticide per surface area of the weed leaves if the pesticide acts mainly through contact and the pore water concentration in the top centimetre of soil if the pesticide acts mainly through uptake from the soil. With respect to the temporal dimension of the EREQs it is proposed to again use the annual peak value of the EREQ. The type of spatial unit of the EAG to consider concerns the operational edge- of field strip near a treated field, and for the recovery option also the operational nearby off-field strip (see Figure 1). We propose consideration of two options with respect to the width of the operational edge-of-field strip and the operational nearby off-field strip: either the first $10 \mathrm{~cm}$ of this strip/area or the first $2-\mathrm{m}$ width of this strip/area. The first $10 \mathrm{~cm}$ will of course lead to higher exposure than the $2-\mathrm{m}$ width of this area. Note that the inner border of the operational edge-of-field strip by definition is the field margin, but that the location of the inner border of the operational nearby off-field area has to be selected in consultation with risk managers. If for example the inner border of the operational nearby off-field area is set at a $5 \mathrm{~m}$ distance from the field margin, the spatial unit of the EREQ to consider for the operational nearby off-field strip concerns the strip between $5-5.1 \mathrm{~m}$ in the first option or between $5-7 \mathrm{~m}$ in the second option. 
There is also variability in the EREQ along the length of the field margin because there may be considerable variation in the spray drift deposition (van de Zande et al., 2006). Following the same line of thinking as for the weeds in the treated field, the proposed average length is $10 \mathrm{~cm}$.

The spatial statistical population of the spatial units consists of all operational edge-of-field strips (and for the population recovery SPG option also the operational off-field strips) of the agricultural fields where this pesticide is applied (of course restricted to the area of use of the substance). The consequence of this choice is that this population will usually include a considerable fraction of zero values for the EREQ because the off-field exposure routes are driven by factors such as wind and runoff that act in a certain direction (i.e. no exposure upwind in case of spray drift and no exposure uphill in case of runoff). The multi-year temporal population of EREQ values is proposed to consist only of values from the years in which the pesticide is applied, as these years generate the maximum EREQ values. The other years are likely to generate zero values or values close to zero. It is proposed to take the $90^{\text {th }}$ percentile from the spatio-temporal population of EREQ values without prescribing any restrictions to the spatial or temporal percentiles. In principle, this $90^{\text {th }}$ percentile may be replaced by e.g. a $70^{\text {th }}$ or $80^{\text {th }}$ percentile but the $90^{\text {th }}$ percentile has become more or less a standard approach in the EU regulatory exposure assessment. 


\section{$5 \quad$ Current decision schemes for risk assessment}

\section{$5.1 \quad$ Effect assessment scheme}

\subsubsection{Data requirements in EU Commission Regulations}

\section{Screening data}

Screening data shall establish whether test substances exhibit herbicidal or plant growth regulatory activity. The data shall include testing from at least six plant species from six different families. The tested concentration and rates shall be equal to or higher than the maximum recommended application rate and at a rate either to simulate use pattern under field conditions, with testing conducted after the final treatment, or at a rate applied directly that takes into account the accumulation of residues following multiple applications of the plant protection product. Many species can be used for plant testing, either crop or non-crop. Table 1 lists species that are historically used in plant testing.

For assessment of active substances with herbicidal or plant growth regulation activity a more advanced testing is always required, but screening data may suffice for other active substances (e.g. fungicides, insecticides). If the screening data show clear effects on at least one of the non-target plants, further testing may be required.

The effects of formulated plant protection products on non-target plants shall be reported, if the toxicity of the plant protection product cannot be predicted on the basis of the data for the active substance, unless the applicant shows that no exposure occurs. A list of species historically used in terrestrial plant testing is presented in Table 1. 
Table 1 Species historically used in terrestrial plant testing

\begin{tabular}{|c|c|c|}
\hline Family & Species & Common names \\
\hline \multicolumn{3}{|l|}{ DICOTYLEDONAE } \\
\hline Chenopodiaceae & Beta vulgaris & Sugar beet \\
\hline Compositae (Asteraceae) & Lactuca sativa & Lettuce \\
\hline Cruciferae (Brassicaceae) & Sinapis alba & Mustard \\
\hline Cruciferae (Brassicaceae) & Brassica chinensis & Chinese cabbage \\
\hline Cruciferae (Brassicaceae) & Brassica napus & Oilseed rape \\
\hline Cruciferae (Brassicaceae) & Brassica oleracea var: capitata & Cabbage \\
\hline Cruciferae (Brassicaceae) & Brassica rapa & Turnip \\
\hline Cruciferae (Brassicaceae) & Lepidium sativum & Garden cress \\
\hline Cruciferae (Brassicaceae) & Raphanus sativus & Radish \\
\hline Cucurbitaceae & Cucumis sativa & Cucumber \\
\hline Leguminosae (Fabaceae) & Glycine $\max$ (G. soja) & Soybean \\
\hline Leguminosae (Fabaceae) & Phaseolus aureus & Mung bean \\
\hline Leguminosae (Fabaceae) & Pisum sativum & Pea \\
\hline Leguminosae (Fabaceae) & Trigonella foenum-graecum & Fenugreek \\
\hline Leguminosae (Fabaceae) & Lotus corniculatus & Birdsfoot trefoil \\
\hline Leguminosae (Fabaceae) & Trifolium pratense & Red Clover \\
\hline Leguminosae (Fabaceae) & Vicia sativa & Vetch \\
\hline Solanaceae & Lycopersicon esculentum & Tomato \\
\hline Umbelliferae (Apiaceae) & Daucus carota & Carrot \\
\hline \multicolumn{3}{|l|}{ MONOCOTYLEDONAE } \\
\hline Gramineae (Poaceae) & Avena sativa & Oats \\
\hline Gramineae (Poaceae) & Hordeum vulgare & Barley \\
\hline Gramineae (Poaceae) & Lolium perenne & Perennial ryegrass \\
\hline Gramineae (Poaceae) & Oryza sativa & Rice \\
\hline Gramineae (Poaceae) & Secale cereale & Rye \\
\hline Gramineae (Poaceae) & Sorghum vulgare & Shattercane, Grain sorghum \\
\hline Gramineae (Poaceae) & Triticum aestivum & Wheat \\
\hline Gramineae (Poaceae) & Zea mays & Corn \\
\hline Liliaceae (Amarylladaceae) & Allium cepa & Onion \\
\hline
\end{tabular}

\section{Toxicity tests with non-target plants}

For active substances, and when relevant the formulated plant protection products, that exhibit herbicidal or plant growth regulatory activity, vegetative vigour and seedling emergence concentration/response tests shall be provided for at least six species representing families for which herbicidal/plant growth regulatory action has been found. Where, from the mode of action, it can be clearly established that either seedling emergence or vegetative vigour is affected, only the relevant study shall be conducted. The described test conditions and data requirements in EC (2013b; 2013c) concern dose-response tests on a selection of 6 to 10 monocotyledon and dicotyledon plant species representing as many taxonomic groups as possible allowing for each test species to calculate an ER50 (effective rate causing $50 \%$ effect on the measurement endpoint of the non-target plant).

Note: According to Ctgb (2014), data on risk to terrestrial non-target plants are not always required. Where exposure is negligible, no data need to be submitted, e.g., in the case of:

- Rodenticides

- Seed treatments

- Granules

- Bulb dipping

- Drenching treatment

- Substances used to cover and cure pruning wounds

- Substances that are used in stored products 


\section{OECD test guidelines}

An overview of current OECD test guidelines 208 and 227 (OECD, 2006a; OECD 2006b) is given.

OECD 208: Terrestrial Plant Test - Seedling Emergence and Seedling Growth Test

Depending on the expected route of exposure, the test item is either incorporated into the soil (usually done e.g. for veterinary medicinal) and seeds planted in this treated soil, or the test item is applied to the soil surface (usually done for plant protection products) after sowing. The test item concentration has to be confirmed analytically. After application the plants are evaluated weekly for effects (phytotoxicity) in comparison to the water-treated control plants for 14 to 21 days after $50 \%$ emergence of the seedlings in the control group. At the test end the endpoints (e.g. fresh weight, dry weight, height of shoots) are measured and recorded (Figure 6). Note that US EPA test protocols focus on similar endpoints but that test duration may be up to 28 days.

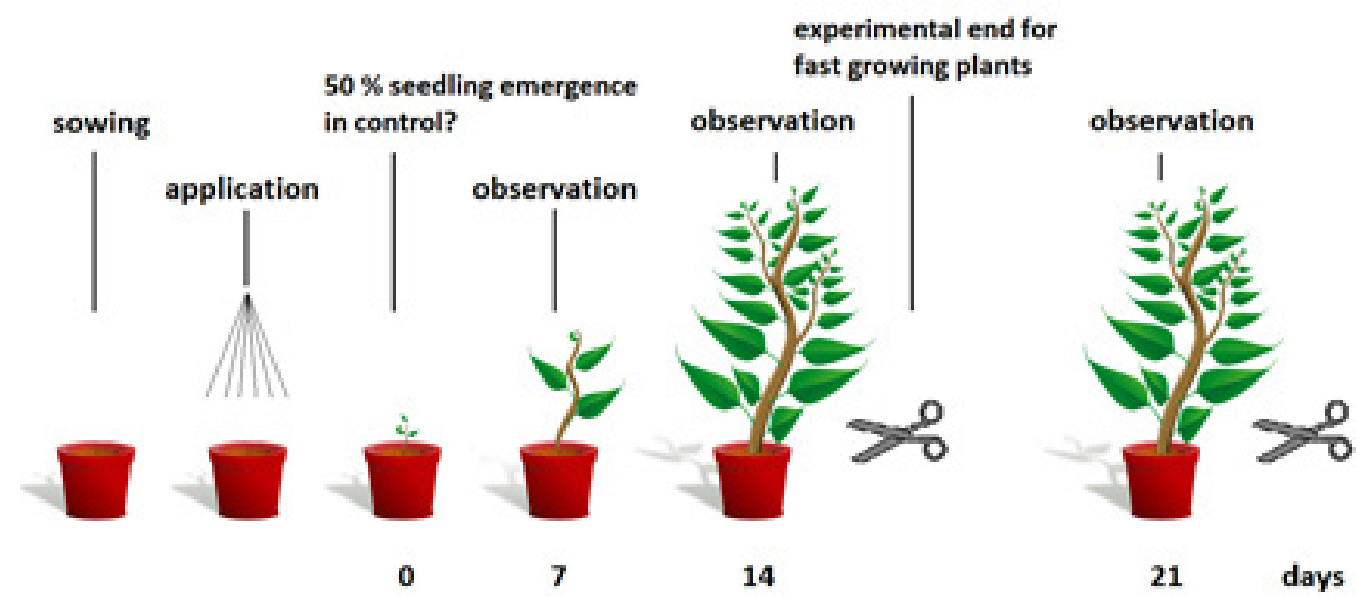

Figure 6 Overview of conduct OECD test 208 (figure from www.ibacon.com)

In the case of veterinary medicinal products the test item can be applied to manure to have a more realistic approach (concept development for an extended plant test in the environmental risk assessment of veterinary medicinal products). This manure is then incubated under anaerobic conditions. The incubation time depends on the type of manure (cattle, pig) and its normal storage time. The spiked manure is then incorporated into the soil. The further study design has to fulfil the requirements of OECD 208. The effects are evaluated in comparison to a manure treated control.

Endpoints are germination, mortality and fresh weight. If the test is conducted as a multiple rate test, effects on fresh weight are reported as $E_{x}$ (effective rate) for each species individually, or if the test is conducted as a limit test, as NOER (no observed effect rate). Additional parameters that can be assessed are height and dry weight of shoots. Effects on these parameters are reported as $E R_{x}$ for each species individually. Phytotoxicity (e.g. chlorosis, necrosis, abnormal growth, growth reduction) and growth stages (BBCH code) are recorded.

OECD 227: Terrestrial Plant Test - Vegetative Vigour Test

Plants are grown from seeds to the 2- to 4-true leaf stage. Sowing takes place on different dates to ensure that all species are in this stage on the application day. The test item is then sprayed onto the seedlings. The test item concentration has to be confirmed analytically. After the application, the plants are evaluated weekly for effects (phytotoxicity) in comparison to water-treated control plants for 21 to 28 days after treatment. At the test end the endpoints are measured and recorded. Note that US EPA test protocols focus on similar endpoints. 


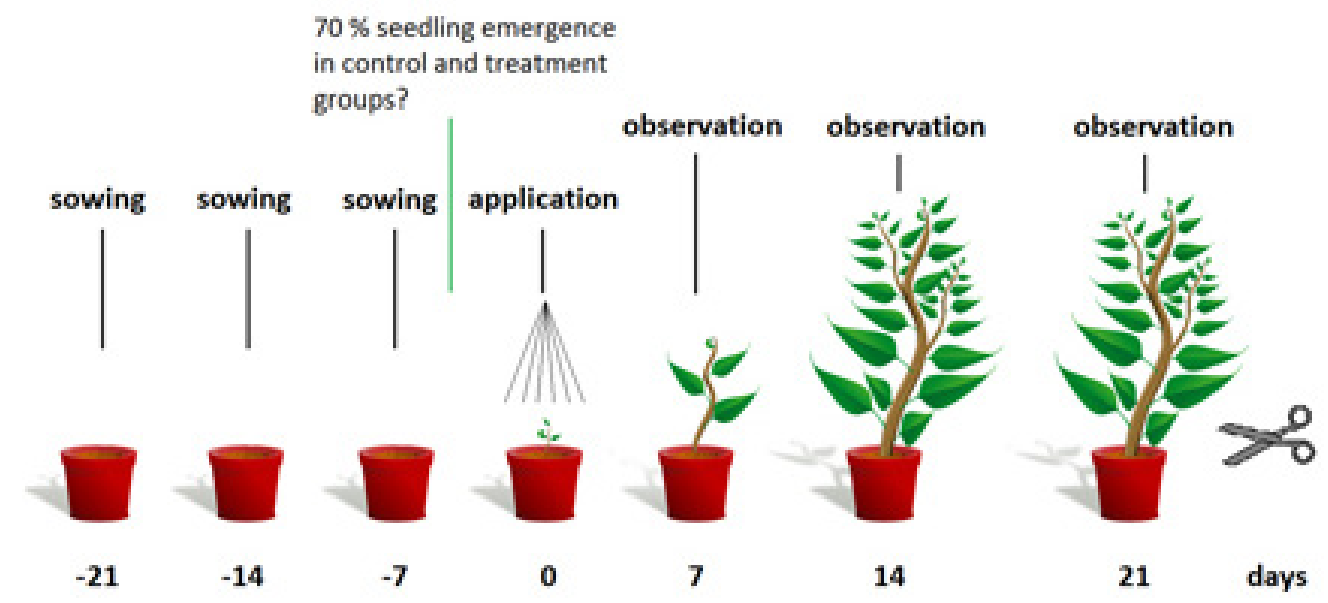

Figure 7 Overview of conduct OECD test 227 (figure from www.ibacon.com)

Endpoints are mortality and fresh weight of shoots. If the test is conducted as a multiple rate test, effects on fresh weight are reported as $E_{x}$ (effective rate) for each species individually or if the test is conducted as limit test as NOER (no observed effect rate). Additional parameters that can be assessed are height and dry weight of shoots. Effects on these parameters are reported as $E R_{x}$ for each species individually. Phytotoxicity (e.g. chlorosis, necrosis, abnormal growth, growth reduction) and growth stages (BBCH code) are recorded. As such the tests do not cover all chronic effects or effects on reproduction (i.e. seedset, flower formation, fruit maturation).

Both OECD tests 208 and 227 are conducted in controlled conditions of temperature, moisture and light, and usually on artificial soil.

\subsubsection{Effect assessment scheme in the Guidance Document on Terrestrial Ecotoxicology}

A summary is given of the SANCO guidance document on terrestrial ecotoxicology (SANCO, 2002).

Test substance

The test substance should be the lead formulation (or another formulation) because formulations contain, besides the active substance, all other components and coadjuvants. For systemic products applied on the ground/soil, the tests should reproduce this application pattern.

Tiered environmental effect assessment

Tier-1 assessment is based on information from initial screening data. The endpoints measured in most screening studies (e.g. phytotoxicity, chlorosis) cannot be interpreted as a NOEC or NOER covering germination and biomass production. However, the available information usually allows the use of a conservative approach (e.g. observing effects of at least $50 \%$ phytotoxicity in the most sensitive test species compared to controls). If the results show more than $50 \%$ effect for one species or clear indications of effects on more than one species, data requirements and assessment move to the next tier.

For the evaluation of Tier 1, the effective concentration ECx or effective application rate ERx (e.g. EC25, ER25, EC50, ER50) are determined for the most sensitive parameter(s) of interest, i.e.:

- Emergence, biomass and/or visual effects compared to unexposed controls for the seedling emergence test,

- Biomass of surviving plants, height of the shoots, as well as abnormalities in the appearance of young plants, stunted growth, chlorosis, discoloration, mortality and effects on plant development for the vegetative vigour test. 
The Tier-2 assessment follows a TER approach (toxicity/exposure ratio). Both effects and exposure are expressed in terms of application rate $(\mathrm{g} / \mathrm{ha})$. Effects are represented by ER50 values from tests performed with 6 to 10 test species. There are two options, a deterministic and probabilistic approach, from which a choice should be made with regard to the data set. In the deterministic approach the TER based on the most sensitive species should be greater than 5 . This trigger of 5 presupposes that at least 6 species have been tested. The trigger may be reduced if information on more species is available. The probabilistic approach makes use of the species sensitivity distribution (SSD) approach if data from 6-10 species are available. If the ER50 for less than 5\% of the species (HR5) is below the highest predicted exposure level, the risk for terrestrial plants is assumed to be acceptable.

The Tier-3 assessment requires semi-field or field assays. Field or semi-field studies with non-target terrestrial plants are not standardised. Generally, effects on plant abundance and biomass production at different distances from the crop or at exposure levels representing different distances from the crop should be analysed. Glasshouse or field studies might be used to study the effects observed on non-target plants during realistic applications. These studies are not standardised and protocols are usually proposed by notifiers and might be discussed with national agencies.

\subsubsection{Proposed specific protection goals and effect assessment schemes in the EFSA scientific opinion on non-target terrestrial plants}

\section{I ntroduction}

In the scientific opinion addressing the state of the science on risk assessment of plant protection products for non-target terrestrial plants (EFSA PPR 2014), ecosystem services for weeds/non-target terrestrial plants both in-field and off-field habitats are discussed. Specific protection goal options, however, were developed for non-target terrestrial plants in off-field habitats only. EFSA PPR (2014) proposed consideration of both vegetative and generative assessment endpoints as attributes for several types of non-target terrestrial plants (see key driver groups and Table 2 below).

\section{Description of key driver group}

In the scientific opinion addressing the state of the science on risk assessment of plant protection products for non-target terrestrial plants (EFSA PPR 2014) the following key drivers (= SPUs = Service Providing Units) for non-target terrestrial plants are mentioned for off-field ERA:

- woody and herbaceous vascular plants (flowering plants, ferns, horsetails),

- liverworts

- mosses

- lichens

Table 2 Specification of the ecological assessment goal using 5 dimensions.

\begin{tabular}{|c|c|c|}
\hline Dimension & Option & Remark \\
\hline Ecological entity & Populations & $\begin{array}{l}\text { It is assumed that protection of populations in edge-of-field } \\
\text { habitats also protects biodiversity of non-terrestrial plants in } \\
\text { the landscape }\end{array}$ \\
\hline Attribute(s) & $\begin{array}{l}\text { Growth/reproduction - } \\
\text { abundance/biomass }\end{array}$ & $\begin{array}{l}\text { In the SANCO Guidance Document on Terrestrial } \\
\text { Ecotoxicology the focus was on vegetative and not on } \\
\text { reproductive endpoints }\end{array}$ \\
\hline Magnitude of effect & Negligible & $\begin{array}{l}\text { This implies that the effect assessment should be based on } \\
\text { NOER/ER } 10 \text { values and not on ER50 as was done in the } \\
\text { SANCO GD }\end{array}$ \\
\hline Temporal scale & $<$ days & $\begin{array}{l}\text { If the allowable magnitude of effect is negligible this also } \\
\text { means that the temporal scale should be small }\end{array}$ \\
\hline
\end{tabular}




\section{Exposure considered in the effect assessment}

In EFSA PPR (2014) the effect assessment approaches discussed are based on toxicity experiments with non-target terrestrial plants in their juvenile stage that are sprayed once (simulating spray drift) at different rates relative to the field application rate or with soils that are sprayed in which seeds are planted (although the latter approach is hardly discussed in EFSA PPR, 2014). Consequently the measurement endpoints in the effect assessment usually concern $E_{x}$ values (application rate that causes $\mathrm{x} \%$ effect) or NOERs (No Observed Effect application Rates). This is in accordance with the EREQ defined in terms of mass of substance per surface area (e.g. g/ha), although for a single application only, which can be linked to the drift exposure routes but not to the run-off exposure route. In principle, however, potted plant experiments can be performed with spiked soil so that the effects can be expressed in terms of pore water concentration, but this is not currently done routinely.

\section{Selection of test species}

Data requirements that need to be provided (see EC, 2013 b\&c) concern both crop and non-crop terrestrial plant species. Several experiments have demonstrated that crop species may be suitable surrogates for wild species (herbaceous and woody) when tested at the juvenile stage under similar conditions. However, some woody and herbaceous species are very sensitive when sprayed at the reproductive stage (e.g. with sulfonyl urea herbicides). Current test guidelines (e.g. OECD, 2006 a\&b) do not focus on reproductive endpoints of non-target terrestrial plants.

Many non-crop species can germinate readily and uniformly under greenhouse conditions with minimum requirements, and are deemed suitable for phytotoxicity testing. Annual and perennial species do not consistently differ in their sensitivity to herbicides. There is however a paucity of data on herbicide effects on ferns, mosses and lichens and a few studies show that they may be sensitive.

\section{Operational protection goal}

In EFSA PPR (2014) the operational protection goal for non-target terrestrial plants in edge-of-field habitats is assumed to be achieved when $95 \%$ of the plant populations in off-field habitats will be protected from the use of plant protection products. Note that when linking exposure to effects the specification of the exposure assessment goal should be considered as well $\left(90^{\text {th }}\right.$ percentile of the distribution of the exposure quantity by the dominant exposure route spray drift). Because it is intended to protect plant populations, EFSA PPR (2014) recommends assessment of both vegetative and reproductive endpoints (and to select the most sensitive) as well as use of the ER10 or NOER instead of the ER50 in the effect assessment.

\section{Effect assessment}

If only ER50 values for vegetative endpoints are available for 6 or more species the Ecological Relevant Endpoint (ERE) in the effect assessment is the $5^{\text {th }}$ percentile of the SSD constructed with ER50 values ( $=\mathrm{HR} 5_{\mathrm{ER} 50 ; \mathrm{veg}}$ ) divided by an extrapolation factor (EF) for going from ER50 vegetative endpoints to EC10 endpoints including reproductive effects.

$\mathrm{ERE}=\mathrm{HR} 5_{\mathrm{ER} 50 ; \mathrm{veg}} / \mathrm{EF}$

According to EFSA PPR (2014; Appendix A in this document) the average ratio between ER50 values for vegetative endpoints and the ER10 values for reproductive endpoints is 36 (46 combinations are available for these endpoints and several herbicides). The $50^{\text {th }}$ percentile of this ratio is approximately 5. The assumptions behind the derivation of the extrapolation factor (EF) need to be verified.

Alternatively, the Ecological Relevant Endpoint (ERE) in the effect assessment is the $5^{\text {th }}$ percentile of the SSD constructed with ER10 or NOER values, selecting the most sensitive vegetative or reproductive endpoint for each species ( $=\mathrm{HR} 5_{\mathrm{ER} 10 \text {; veg or repro }}$ ). It may be necessary to prolong vegetative growth studies to also provide the reproductive endpoints (i.e. to 28 days).

Note that EFSA PPR (2014) also states that an assessment factor (AF) needs to be applied to the Ecological Relevant Endpoint (ERE) to cover for other uncertainties (e.g. the transition from laboratory to field, single species to biocoenosis) in the risk assessment and that both factors (EF and AF) should 
be calibrated on the basis of data from the reference tier (actual field test or semi-field test as surrogate reference tier).

The EFSA PPR (2014) opinion discusses higher tier options but did not develop guidance on how to interpret field and semi-field studies conducted with herbicides and how to use measurement endpoints in the risk assessment.

\subsubsection{Recommendations from two recent SETAC Europe workshops}

Recently two SETAC Europe workshops (April 2014, Sept 2015) were organised with the aim of:

- developing a framework for a higher-tier approach to assessing the risk of PPPs to NTTPs;

- providing expert opinion and advice as input for the ongoing revision of the terrestrial ecotoxicology guidance document and NTTP risk assessment procedures.

\section{Agreed recommendations from the $1^{\text {st }}$ workshop}

The recommendations agreed to in the first workshop (Arts et al., 2015) relate to the three main themes, i.e. specific protection goals, risk assessment and mitigation. The participants of the workshop adopted the EFSA approach of using an ecosystem services framework for identifying specific protection goals. The workshop participants agreed that the type and relative importance of ecosystem services provided by NTTPs differ between areas both in-field and off-field. A number of concerns were raised during the workshop and literature reviews were performed and data collected in order to reduce uncertainty. These actions focussed on the protectiveness of standard test species for wild species, the protectiveness of regulatory endpoints for reproductive endpoints, the methods and endpoints for multispecies or field-studies and the importance of different exposure routes for nontarget terrestrial plants. The report of the first workshop is currently in a commentary round with workshop participants. The second workshop built upon the results of literature reviews, the recommendations of the first workshop and the EFSA opinion on risk assessment of PPPs for NTTPS. The main charge questions identified for the second workshop were: how to address reproductive endpoints, how to mitigate risks and how to conduct higher tier tests. Preliminary comparative analysis of reproductive and vegetative endpoints indicates that the reproductive endpoints (mainly seed number and seed biomass as measures of seed production) are on average less than a factor of 2 more sensitive than the vegetative endpoints (vegetative vigour, biomass) when comparing the same point estimate (i.e. ER10, ER25 or ER50 each). This conclusion was independent of datasets. It was agreed to perform a definitive analysis of a full dataset. Investigation of the possibility of predicting which PPP have a much larger impact on reproduction than on vegetative growth, and to derive assessment factors from the analysis of the full data set, was also agreed. A further need was identified for criteria to evaluate and interpret field studies in the context of Specific Protection Goals. A framework for a higher tier risk assessment for NTTPs was proposed, in including standard tests, tests with additional species, population and community-level experiments and models and field studies and landscape-level models. The workshop reports will be submitted to EFSA for consideration in the preparation of the guidance document on Terrestrial Ecotoxicology starting in the second half of 2016.

\section{Agreed recommendations from the second workshop}

Ecosystem services

The workshop participants agreed that 'food web support' is an important ecological function that should be protected. Most workshop participants considered 'food web support' as being addressed in the classification system of the ecosystem services approach.

Effects on reproduction:

- Surrogate assessment endpoints are flowering, seed production and seed germination. Vegetative reproduction is addressed via the biomass tests. Preliminary comparative analysis of reproductive and vegetative endpoints indicates that the reproductive endpoints (mainly seed number and seed biomass as measures of seed production) are on average less than a factor of 2 more sensitive than the vegetative endpoints (vegetative vigour, biomass) when comparing the same point estimate (i.e. ER10, ER25 or ER50 each). This conclusion was independent of dataset; a definitive analysis of the full dataset will be performed. 
The preliminary analysis described above suggests that reproductive endpoints may be covered by applying an appropriate extrapolation factor to the vegetative vigour endpoints (e.g. ER50 or ER10). However, in cases where reproductive endpoints are expected to be much more sensitive than vegetative endpoints, reproduction studies may be necessary.

A further analysis will be performed on the datasets under investigation, concerning whether it is possible to predict which PPP have a much larger impact on reproduction than on vegetative growth. Assessment factors will be derived from the analysis of the full data set.

- Most data show that early stage Vegetative Vigour testing also covers reproductive effects. Additional data may be proposed to cover potential effects on reproduction, for example for specific Modes of Action. Data analysis is still ongoing. Modelling studies should be conducted to translate reductions in seed production/germination to effects on population size to link the test endpoints to the specific protection goals. Based on an initial analysis of sensitivities of wild versus crop species (Christl, 2015), testing with standard crop species appears to be protective of wild species.

A definitive analysis of the dataset will be performed to account for further extension of the dataset and re-assessment of the statistics emerging from the dataset.

Lower and higher tier testing

- There is a need for criteria to evaluate and interpret field studies in the context of SPGs.

- There is a need for defining a (surrogate) reference tier in order to calibrate the tiered approach.

- For defining a reference community for an EU-level risk assessment, a trait-based approach seems promising. Traits should be linked to the ecosystem services provided by NTTPs.

\subsection{Exposure assessment scheme}

\subsubsection{Exposure assessment in the Guidance Document on Terrestrial Ecotoxicology}

Spray drift is considered the key exposure route for terrestrial plants located in the vicinity of the treated area. Spray drift models may be used as a surrogate to cover the exposure assessment. The SANCO guidance document (SANCO, 2002) mentions buffer strips and drift-reducing application techniques as risk mitigation options.

\subsubsection{Exposure assessment in the current Dutch risk assessment}

In the Dutch risk assessment the exposure is also based only on spray drift. According to Ctgb (2014), the initial exposure of non-target plants should be determined at the following distances from the centre of the last crop row:

- Field crops (including 'soft fruit' and bush and hedge shrubbery) and soil applications, as in the case of herbicides: $2 \mathrm{~m}$ ( $1 \mathrm{~m}$ from the edge of the parcel) (evaluation zone $1.5-2.5 \mathrm{~m}$ );

- $3 \mathrm{~m}$ for large fruit (evaluation zone 2.5 - $3.5 \mathrm{~m}$ )

- $5 \mathrm{~m}$ for lane trees (evaluation zone 4.5 - $5.5 \mathrm{~m}$ ).

For these distances the following drift percentages apply in the Netherlands:

- Outdoor field cultures and soil applications: $4.7 \%$

- Large fruit: $37 \%$ before 1 May; $15.9 \%$ after 1 May (the latter value (15.9\%) is also used for grapes and small fruit (irrespective of application time)

- Lane trees; 'spillen' (closely spaced): $1.8 \%$ and 'opzetters' (widely spaced): $6.3 \%$ in case of a cropfree zone of $5 \mathrm{~m}$ (LOVT))

Where the crop free zones exceed the standard distances from the centre of the last crop row mentioned here, the 'off-field' area only starts after the crop-free zone and the drift percentage must be determined at a distance as large as the crop-free zone. 
Where natural objects have been placed to reduce the amount of drift (e.g. a wind hedge) this object should not be considered as part of the off-field area that needs to be protected. It must be kept in mind that those crop-free zones and natural objects in many cases are only applied on those parts of parcels that border water courses. Protection of non-target terrestrial plants is needed for all sides of a parcel.

Ctgb (2014) does not define the elements of the exposure assessment goal for non-target plants. Thus, the above drift percentages are not consistent with the approach proposed in the EFSA protection goal opinion (EFSA PPR, 2010).

According to Ctgb (2014) in cases where only exposure by the soil is relevant (e.g. when an active substance has only adverse effects on pre-emergence stadia of non-target plants) some interception by the off-crop vegetation may be taken into account. For the time being the following interception percentages are applied which are considered realistic worst-case: December - February 20\%; March $30 \%$; April $40 \%$; May - September $50 \%$; October $40 \%$. 


\section{Implementation plan and research needs}

In this report several options for Specific Protection Goals (SPGs) and for Exposure Assessment Goals (EAGs) are proposed. Interaction with the risk manager is needed to provide further information to the risk manager about the proposed SPGs and EAGs. In the end the risk manager decides upon these goals. Interaction with risk managers might lead to a refinement or further elaboration of the SPGs and EAGs proposed.

Consequences of the proposed protection goals for the admission of pesticides into The Netherlands and possible impact on crop yields are not evaluated at this time. This is part of further work by e.g. industry.

Further research includes operationalisation of the nearby off-field area if the population recovery option is selected as SPG. Moreover, the proposed specification of the EAGs in terms of a spatiotemporal percentile will require the development of a probabilistic exposure assessment procedure. 


\section{$7 \quad$ Conclusions}

In this report three options for in-field Specific Protection Goals (SPGs), three options for off-field Specific Protection Goals (SPGs) and two options for related Exposure Assessment Goals (EAGs) are proposed. SPGs are defined in terms of effects of weed control on the ecosystem service 'crop production' and protection of 'beneficial' non-target plants and other ecosystem services they provide, including contribution of weeds to local biodiversity. In the off-field area, options are defined in terms of protecting vegetative and generative endpoints of terrestrial plants and their provision of ecosystem services and the expected sustainability of plant populations at the local and landscape level. Two EAG spatial unit options are proposed for exposure assessment in edge-of-field strips and habitats in the nearby off-field area.

Further discussions are needed with risk managers concerning options for Specific Protection Goals and the associated Exposure Assessment Goals. The consequences for the admission of pesticides in The Netherlands need to be quantified. Further operational definitions of the nearby off-field areas are needed. 


\section{References}

Alix A, Bakker F, Barrett K, Brühl CA, Coulson M, Hoy S, Jansen JP, Jepson P, Lewis G, Neumann P, Süßenbach D, Van Vliet $P$ (Eds.) (2012). ESCORT 3 - linking non-target arthropod testing and risk assessment with protection goals. CRC SETAC Press, $151 \mathrm{pp}$.

Arts, Gertie H.P., Margit Dollinger, Eva Kohlschmid, Lorraine Maltby, Hugo Ochoa-Acuña, Véronique Poulsen, 2015. An ecosystem services approach to pesticide risk assessment and risk management of non-target terrestrial plants: recommendations from a SETAC Europe workshop. Environ. Sci. Pollut. Res. 2: 2350-2355.

CBS (2015). Centraal Bureau voor de Statistiek. www.cbs.nl.

Cormont A, Siepel H, Clement J, Melman TCP, WallisDeVries MF, van Turnhout CAM, Sparrius LB, Reemer M, Biesmeijer JC, Berendse F, De Snoo GR (2016). Landscape complexity and farmland biodiversity: Evaluating the CAP target on natural elements. Journal of Nature Conservation 30 : 19-26.

Christl, H. 2015. Comparative assessment of the sensitivity of wild plant and crop species. Tier3 solutions $\mathrm{GmbH}$ Tier3 report number B14037. 142 pp.

Ctgb (2014). Evaluation Manual for the Authorisation of plant protection products and biocides according to Regulation (EC) No 1107/2009. EU part Plant protection products. Chapter 7 Ecotoxicology: terrestrial; non-target arthropods and plants, version 2.0, $36 \mathrm{pp}$.

EC (2010). The CAP towards 2020: meeting the food, natural resources and territorial challenges of the future. http://ec. europe.eu/agriculture/cap-post-2013/communication/index.en.htm.

EC (2013a). CAP Reform-an explanation of the main elements. EC/MEMO/13/621.

EC (2013b). Commission Regulation (EU) No 283/2013 of 1 March 2013 setting out the data requirements for active substances, in accordance with Regulation (EC) No 1107/2009 of the European Parliament and of the Council concerning the placing of plant protection products on the market. Official Journal of the European Union L 93/1-84.

EC (2013c). Commission Regulation (EU) No 284/2013 of 1 March 2013 setting out the data requirements for plant protection products, in accordance with Regulation (EC) No 1107/2009 of the European Parliament and of the Council concerning the placing of plant protection products on the market. Official J ournal of the European Union L 93/85-152.

EFSA PPR (2010). Scientific Opinion on the development of specific protection goal options for environmental risk assessment of pesticides, in particular in relation to the revision of the Guidance Documents on Aquatic and Terrestrial Ecotoxicology (SANCO/3268/2001 and SANCO/10329/2002). EFSA J ournal 2010;8(10): 1821, 55 pp.

EFSA PPR (2013). Guidance on tiered risk assessment for plant protection products for aquatic organisms in edge-of-field surface waters. EFSA J ournal 2013;11(7):3290. 268 pp.

EFSA PPR (2014). Scientific Opinion addressing the state of the science on risk assessment of plant protection products for non-target plants. EFSA Journal 20014;12(7):3800, 163 pp 
EFSA SC (2016). Guidance to develop specific protection goal options for environmental risk assessment at EFSA, in relation to biodiversity and ecosystem services. EFSA J ournal $2016 ; 14(6): 4499$.

Hardman CJ, Harrison DPG, Shaw PJ, Nevard TD, Hughes B, Potts SG, Norris K (2015). Supporting local diversity of habitats and species on farmland: a comparison of three wildlife-friendly schemes. Journal of Applied Ecology: doi.1111/1365-2664.12557.

Marshall EJP, Brown VK, Boatman ND, Lutman PJW, Squire GR, Ward LK (2003). The role of weeds in supporting biological biodiversity within crop fields. Weed Research 43: 77-89.

OECD (2006a). OECD 208: OECD guideline for the testing of chemicals. Terrestrial plant test: Seedling emergence and seedling growth test, Adopted 19 July 2006, 21 pp.

OECD (2006b). OECD 227: OECD guideline for the testing of chemicals. Terrestrial plant test: Vegetative vigour test, Adopted 19 July 2006, 21 pp.

SANCO (2002). Guidance Document on Terrestrial Ecotoxicology Under Council Directive 91/414/EEC, SANCO/10329/2002, 25 September 2002 rev1, 37 pp.

Pywall RF, Heard MS, Woodcock BA, Hinsley S, Ridding L, Nowakowski M, Bullock J M (2015). Wildlifefriendly farming increases crop yield: evidence for ecological intensification. Proc R Soc B 282: 20151740.

Storkey J, Westbury DB (2007). Managing arable weeds for biodiversity. Pest Management Science 63:517-523.

Van de Zande JC, Holterman HJ, Michielsen J MGP, Stallinga H (2006). Temporal and spatial variability of spray drift around a sprayed field. Aspects of Applied Biology 77: 295-302.

Van de Zande JC, Holterman HJ, Huijsmans JFM (2012). Spray drift for the assessment of the exposure of aquatic organisms to plant protection products in the Netherlands. Part 1: Field crops and downward spraying. Wageningen, WUR-PRI Report No 419. 
Wageningen Environmental Research

\section{P.O. Box 47}

6700 AA Wageningen

The Netherlands

T +31 (0)317480700

www.wur.nl/environmental-research

Wageningen Environmental Research

Report 2836

ISSN 1566-7197
The mission of Wageningen University and Research is "To explore the potential of nature to improve the quality of life". Under the banner Wageningen University \& Research, Wageningen University and the specialised research institutes of the Wageningen Research Foundation have joined forces in contributing to finding solutions to important questions in the domain of healthy food and living environment. With its roughly 30 branches, 5,000 employees and 10,000 students, Wageningen University \& Research is one of the leading organisations in its domain. The unique Wageningen approach lies in its integrated approach to issues and the collaboration between different disciplines.

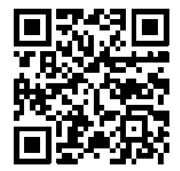





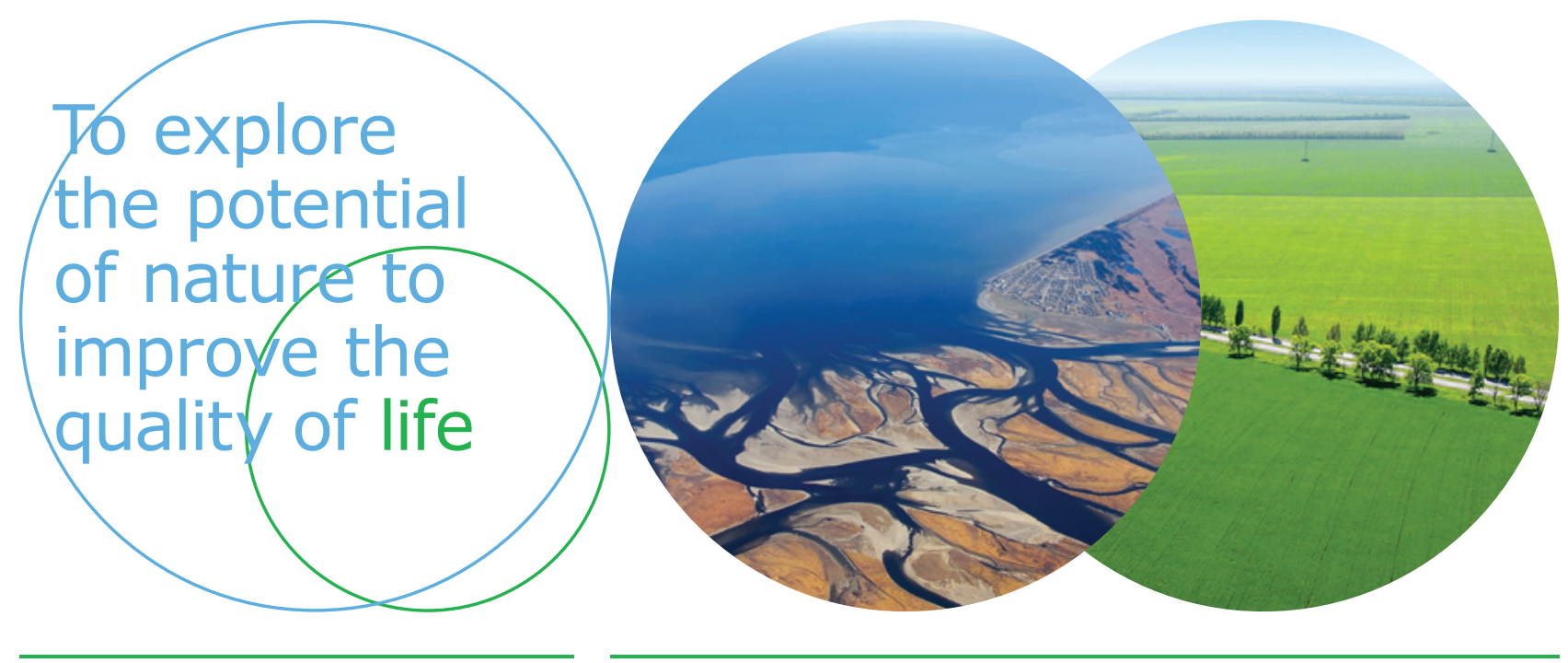

Wageningen Environmental Research P.O. Box 47

$6700 \mathrm{AB}$ Wageningen

The Netherlands

$\mathrm{T}+31(0) 317480700$

www.wur.eu/environmental-research

Report 2836

ISSN 1566-7197
The mission of Wageningen University and Research is "To explore the potential of nature to improve the quality of life". Under the banner Wageningen University \& Research, Wageningen University and the specialised research institutes of the Wageningen Research Foundation have joined forces in contributing to inding solutions to important questions in the domain of healthy food and living environment. With its roughly 30 branches, 5,000 employees and 10,000 students, Wageningen University \& Research is one of the leading organisations in its domain. The unique Wageningen approach lies in its integrated approach to issues and the collaboration between different disciplines. 